\title{
Transitions in Problematic Internet Use: A One-Year Longitudinal Study of Boys
}

\author{
Bo Young Choi', Sun Huh², Dai-Jin Kim³ , Sang Won Suh'1, Sang-Kyu Lee ${ }^{4,5}$, and Marc N. Potenza ${ }^{5,6,7}$ \\ ${ }^{1}$ Department of Physiology, College of Medicine, Hallym University, Chuncheon, Republic of Korea \\ ${ }^{2}$ Department of Parasitology, College of Medicine, Hallym University, Chuncheon, Republic of Korea \\ ${ }^{3}$ Department of Psychiatry, Seoul St. Mary's Hospital, The Catholic University of Korea School of Medicine, Seoul, Republic of Korea \\ ${ }^{4}$ Department of Psychiatry, College of Medicine, Hallym University, Chuncheon, Republic of Korea \\ ${ }^{5}$ Departments of Psychiatry, Neuroscience and Child Study, Yale University School of Medicine, New Haven, CT, USA \\ ${ }^{6}$ National Center on Addiction and Substance Abuse, Yale University School of Medicine, New Haven, CT, USA \\ ${ }^{7}$ Connecticut Mental Health Center, New Haven, CT, USA
}

\begin{abstract}
Objective Longitudinal studies may help elucidate the factors associated with Problematic Internet Use (PIU); however, little prospective research has been conducted on the subject. The aim of the current study was to prospectively examine PIU in children/adolescents and identify the possible risk factors associated with transitions in PIU severity.

Methods 650 middle-school boys were surveyed at two points one year apart and assessed for PIU using the Internet Addiction Proneness Scale for Youth (KS-II) and on other psychological characteristics.

Results We found that $15.3 \%$ at baseline and $12.4 \%$ at one year met the criteria for at-risk/high-risk PIU (ARHRPIU). Both the persistent-ARHRPIU and emerging-ARHRPIU groups revealed greater depressive, motor impulsive, and smart-phone-addiction tendencies than the remitting-ARHRPIU group or the persistent low-risk group. In addition, we found that individuals exhibiting higher hyperkinetic attention-deficit/hyperactivity disorder (ADHD) scores were less likely to remit from ARHRPIU, and that individuals exhibiting more ADHD-related cognitive dysfunction and reporting fewer Internet-game-free days were more likely to demonstrate an emergence of ARHRPIU.

Conclusion The present findings support previous studies in that specific negative-health features are linked to transitions in ARHRPIU. Furthermore, these findings suggest that intervention is needed and may be best targeted at specific groups of youths.
\end{abstract}

Psychiatry Investig 2019;16(6):433-442

Key Words Problematic internet use, Internet addiction, Attention deficit hyperactivity disorders, Adolescents.

\section{INTRODUCTION}

Problematic Internet Use (PIU) is characterized by excessive distraction and poor self-control regarding Internet use, leading to problems in multiple areas including at school, at work, family life, as well as in other domains. ${ }^{1-4}$ PIU has been reported in approximately $3-4 \%$ of high-school students and may become an increasingly significant public health con-

Received: July 30, 2018 Revised: January 23, 2019

Accepted: April 2, 2019

$\triangle$ Correspondence: Sang-Kyu Lee, MD, PhD

Department of Psychiatry, College of Medicine, Hallym University, 77 Sakjuro, Chuncheon 24253, Republic of Korea

Tel: +82-33-240-5174, Fax: +82-33-240-5317, E-mail: skmind@hallym.ac.kr

(a) This is an Open Access article distributed under the terms of the Creative Commons Attribution Non-Commercial License (https://creativecommons.org/licenses/by$\mathrm{nc} / 4.0$ ) which permits unrestricted non-commercial use, distribution, and reproduction in any medium, provided the original work is properly cited. cern given the increasing use of digital technologies in the modern world and the current trends in online content. ${ }^{5-7}$ It has been suggested that adolescents are an at-risk population when it comes to Internet-use problems, ${ }^{8}$ because of their developmental immaturity especially in terms of self-control and boundary-setting skills., ${ }^{9,10}$

PIU has been associated with negative psychological factors and comorbidities in retrospective and cross-sectional studies. It may have classically been associated with male teenagers, ${ }^{11}$ especially introspective males, ${ }^{12,13}$ however, similar numbers of females may also experience PIU, ${ }^{5}$ although the types of Internet-use problems (gaming and pornography viewing for males, social networking for females) may vary by gender. ${ }^{14}$ One of the major factors linked to PIU is the amount of time spent on the Internet. ${ }^{15-17}$ However, other factors, such as depression ${ }^{18}$ and impulsiveness ${ }^{19,20}$ (though 
not consistently by age or $\operatorname{sex}^{21}$ ), have also been found to be associated. PIU has been linked with a decreasing amount of time spent in personal relations/interactions and has been positively associated with depression, anxiety, impulse-control disorders, attention-deficit/hyperactivity disorder (ADHD), and substance-use disorders. ${ }^{10,22-24}$ Adolescents with PIU may neglect school work, exhibit low academic achievement, demonstrate increased absenteeism, ${ }^{19}$ and have poor social support. ${ }^{25}$ Cyberbullying behaviors have been linked to PIU, ${ }^{26}$ and negative psychological features have been observed in the victims, perpetrators, and victims-perpetrators of cyberbullying. ${ }^{27}$ Furthermore, PIU may have a negative impact on identity formation, ${ }^{28}$ brain development, ${ }^{29,30}$ and cognitive functioning, ${ }^{31}$ which may lead to low academic performance, engagement in risky activities, ${ }^{32}$ unhealthy dietary habits, ${ }^{33}$ low quality of interpersonal relations, ${ }^{34}$ and self-injurious behavior ${ }^{35}$ in adolescents, ${ }^{36,37}$ although there are few studies investigating the direct effects.

PIU has been proposed as a behavioral addiction with a formal psychiatric diagnosis, with Internet-gaming disorders having been introduced into section III of the Diagnostic and Statistical Manual of Mental Disorders (DSM-5). ${ }^{38}$ Nonetheless, the existence of "Internet addiction" remains a matter of debate, ${ }^{39}$ with gaps in understanding existing with respect to the biological etiology, standardized diagnostic tools, and optimal treatment and preventive approaches. Importantly, it has been suggested that questions regarding which factors (psychological, diagnostic co-occurrences) are causes and which are consequences of PIU may hinder diagnostic and classification efforts, and that longitudinal data are needed to address these questions. ${ }^{40,41}$

Retrospective and cross-sectional research suffer from potential recall bias and do not provide direct insight into changes over time. ${ }^{42}$ Prospective studies may help elucidate factors associated with disease progression and remission, as well as provide data on the incidence of the condition. Despite the strengths of the prospective research model, few investigations of this type have been conducted on PIU. ${ }^{8,43,44}$ Some studies suggest that emotional problems may be a predictor of subsequent PIU, ${ }^{40,41}$ whereas other studies suggest that changes in problematic gaming are not consistently related to changes in psychosocial and emotional factors. ${ }^{43,45}$

The current study was conducted to examine the natural course of PIU in children/adolescents and identify the risk factors associated with transitions in PIU. Numerous studies have reported associations between PIU and psychopathology. As a result of the widespread nature of Internet access, individuals can be constantly connected to a stream of information and can participate in many activities at once. Therefore, individuals afflicted with ADHD, who are easily bored and seek instant gratification, and often have trouble with selfcontrol, may be more vulnerable to Internet addiction. The evidence also indicates that people with ADHD suffer from social $^{46}$ and emotional impairments, ${ }^{47}$ learning disabilities, ${ }^{48}$ and extreme aggression. ${ }^{49}$ These may also be contributing factors influencing the association between PIU and ADHD symptoms. In addition, excessive Internet use may lead to a decrease in communication with those around and depressive symptoms. ${ }^{50}$ In fact, depression appears to be the most commonly reported co-morbid psychiatric condition alongside PIU, being observed relatively consistently in case series and community surveys. ${ }^{51-53}$ Therefore, we hypothesized that mental health concerns, particularly features of $\mathrm{ADHD}$, and temperamental features, specifically greater ADHD severity, aggression, and anger, would be linked to transitions towards greater PIU severity, and high levels of persistent-PIU severity would be associated with depression and school problems. We also explored other features (e.g., main reasons for using the Internet, time free when not Internet gaming) as possible factors that might importantly relate to transitions in PIU severity.

\section{METHODS}

\section{Study design and subjects}

This study consisted of two sessions. In the first session, 650 students in 7 th and 8th grades (age range: $12-14$ years) were recruited from one middle school in Chuncheon, South Korea. The participating school was a single-sex school and so all volunteers in the study were male. After gaining approval from the school principals, investigators visited the schools, explained the purpose of the study to the students and teachers, obtained their informed consent (see below), distributed the questionnaires, and collected them after completion. In the second session, the same students as previously questioned, who were by this time in the $8^{\text {th }}$ and $9^{\text {th }}$ grade, were reevaluated one year later using similar methodologies. This study aimed to investigate the transition from one level of PIU severity to another at baseline and at one-year followup. At baseline, causal factors such as the patterns of Internet use, ADHD scale, aggression, and anger scales were evaluated; the one-year follow-up involved evaluating consequent factors such as suicidal ideation, depression, bullied-bullying, and other addictions (e.g., smartphone addiction). The results of the first session came from the previous survey ${ }^{54}$ and the protocol of the second session trial was submitted to the Ethical Committee of Chuncheon Sacred Heart Hospital (IRB No. 2014-113). Each participant submitted a written informed consent form after receiving a full explanation of the study's purpose and procedure. Before this process, letters were sent through the school to parents informing them of 
the survey method and purpose and outlining the procedure by which they could deny permission for their child to participate in the survey if they wished their child to be excluded. ${ }^{5}$

\section{Instruments}

\section{Demographics and patterns of internet use}

Respondents completed self-reported questionnaires for demographic information (age, academic year) and patterns and main reasons for using the Internet.

\section{Internet addiction proneness scale for youth test (KS-II) ${ }^{55-57}$}

The KS-II scale has 15 items that are scored on a fourpoint Likert scale (1: Not at all to 4: Always). According to the KS-II scale total and subscale scores, students were classified into those with a high risk of PIU, those with a potential risk, and those in a low-risk group, as described previously. 56 High-risk PIU (HRPIU) was defined as a total score of above 44. At-risk PIU was defined as the presence of one of the following: a total score between 41 and 43; a disturbance of adaptive function score of above 14; a withdrawal score of above 12; or a tolerance score of above 12. The low-risk PIU group included those not meeting the above criteria for highrisk or at-risk PIU. In this study, the at-risk/high-risk PIU (ARHRPIU) group included both the high-risk and at-risk groups. The internal-consistency test result (Cronbach's alpha) for the KS-II was 0.83 .

\section{Scales at baseline}

\section{$A D H D$ scale: the short form of the conners well-adolescent} assessment self-report scale (CASS) ${ }^{58}$

This is a 27 -item self-report instrument derived from the long form of the CASS and includes a 12-item ADHD index used to assess probable ADHD. Questions use a four-point Likert-type scaling, ranging from $0=$ not true at all to $3=$ very much true. This measure has been shown to be a valid and reliable self-report tool when used with adolescents. ${ }^{59,60}$ The items include the highest loading items of the long form of the CASS and three generated factors with six items each: conduct problems (high scores indicate a likelihood to break rules and to engage in antisocial activities), cognitive problems (high scores indicate having problems organizing and completing tasks), and hyperactivity problems (high scores indicate having difficulty sitting still or doing the same task for very long). The internal-consistency test result (Cronbach's alpha) for the CASS was 0.92.

\section{Buss-perry aggression questionnaire $e^{61,62}$}

This questionnaire measures aggression and hostility. The questionnaire consists of 29 items that are scored along a five-point Likert scale. The questionnaire provides an overall score, and has four subscales: physical aggression, verbal aggression, anger, and hostility. We only considered the total score in this study (the higher the total score, the greater the severity of the aggression). The internal-consistency test result (Cronbach's alpha) for this questionnaire was 0.92 .

\section{Anger and anger expression (STAXI-K) ${ }^{63}$}

Anger and anger expression were measured using the state-trait anger expression inventory-Korean version (STAXI$\mathrm{K})$. Responses for both trait anger and anger expression range from 0 indicating "almost never" to 3 indicating "almost always." Anger expression is measured by three dimensions reflecting introverted anger, extroverted anger, and anger control. Eight items of introverted anger, called anger-in (inhibition), reflect the frequency that one tolerates or suppresses emotions of anger, and another dimension with eight items of extroverted anger, called anger-out (expression), reflects how often one expresses one's anger to surrounding persons or objects. The other eight items, known as angercontrol (control), reflect how individuals limit or control anger expression. Thus, the anger expression scores range from 0 to 24 in each dimension. The internal-consistency test result (Cronbach's alpha) for the STAXI-K test was 0.87 .

\section{Scales at one-year follow-up}

\section{Reynolds suicidal Ideation questionnaire (SIQ) ${ }^{64}$}

The SIQ, a 30-item self-report tool, was used to assess the suicidal ideation of participants. The respondent is asked to assess the frequency of specific thoughts about suicide and death in the past month. Responses are recorded on a sevenpoint Likert scale ranging from 0 ("I never had this thought") to 6 ("I have this thought almost every day"). The total scale score can range between 0 and 180. The Korean version of the SIQ was standardized by Shin. ${ }^{65}$ The presence of suicidality was defined with higher scores reflecting a greater severity of suicidal ideation. ${ }^{66}$ In this study, the internal-consistency test result (Cronbach's alpha) for SIQ was 0.97.

\section{Beck depression inventory $(B D I)^{67,68}$}

Participants were assessed for depression using the BDI. The BDI consists of 21 items for measuring the subjective severity of depression and the emotional, cognitive, motivational, and physiological symptoms of depression. The Korean version of the BDI was standardized by Hahn et al. ${ }^{69}$ In this study, the internal-consistency test result (Cronbach's alpha) of the BDI was 0.92 . 


\section{Bullying or bullied scale ${ }^{70}$}

Bullying or being bullied was identified using the Korean Bullying or Bullied Scale. This scale is composed of 30 items: 15 for identifying victims (for example, persons who feel left out during recess or lunch time) and 15 for perpetrators (for example, persons who shove and provoke others). Each item was assessed on a five-point scale ( 0 points: never, 1: 1-2 times/month, 2: 2-3 times/month, 3: at least once/week, 4: 2-3 times/week). In this study, the bullying subscale showed a Cronbach's $\alpha=0.914$, and the bullied subscale showed a Cronbach's $\alpha=0.88$.

\section{Smartphone addiction proneness scale (SAPS) $)^{71}$}

The SAPS consists of 15 items scored with a four-point Likert scale (1: "not at all" to 4: "always") and it consists of four subdomains: 1) disturbance of adaptive functions, 2) virtual life orientation, 3) withdrawal, and 4) tolerance. The reliability test of the scale yielded a Cronbach's alpha of 0.880 . In this study, the internal-consistency test result (Cronbach's alpha) of the SAPS was 0.83 .

\section{Barratt impulsiveness scale-11 (BIS-11) $)^{72,73}$}

The BIS-11 assesses impulsivity and uses a four-point Likert scale (1="rarely/never" to $4=$ "almost always/always"). This instrument includes three subscales: cognitive impulsiveness, motor impulsiveness, and non-planning impulsiveness. The Cronbach's alpha coefficient in the current sample was 0.86 .

\section{Statistical analysis}

For all dimensional variables, analyses of variance (ANOVAs) were calculated, followed by pairwise group comparisons with Sheffe's adjustment for multiple testing. The frequencies of the categorical variables were described for the four Internet-use groups of the one-year follow-up (see below). For each categorical variable, comparisons between the one-year-follow-up PIU-severity groups were calculated with binary logistic regressions followed by hierarchical selection for multiple testing. All statistical analyses were performed with SPSS 22 (IBM Corp., Armonk, NY, USA). A significance level of $\mathrm{p}<0.05$ was chosen.

\section{RESULTS}

\section{Prevalence and characteristics of PIU at baseline and at one-year follow-up}

The following results refer to the one-year longitudinal study of 590 students (with a $90.8 \%$ one-year follow-up rate) who participated and provided proper information in the study at both time points. Among the total sample, $15.3 \%$ at baseline and $12.4 \%$ one year later met the criteria for ARHRPIU. Of those with ARHRPIU at baseline, $15.6 \%$ continued to have ARHRPIU (persistent ARHRPIU) and $84.4 \%$ did not (remitting ARPIU group). Among the low-risk students at baseline, 59 students (11.8\%) demonstrated ARHRPIU at one-year follow-up (emerging ARHRPIU). Four hundred and forty-one students ( $74.7 \%$ of the entire sample, $88.2 \%$ of the low-risk at baseline) maintained low-risk use after one year (persistent low-risk Internet use) (Figure 1).

At baseline, the persistent-ARHRPIU group had the highest KS-II, ADHD, and anger-expression scores and the lowest Internet-game-free days per week. The emerging-ARHRPIU group showed higher KS-II scores than the group transitioning to low-risk Internet use (remitting-ARPIU group), although the scores on the withdrawal and tolerance subscales were similar between groups (Table 1).

At one-year follow-up, both the emerging-ARHRPIU and persistent-ARHRPIU groups revealed more depressive, motor impulsive, and smart-phone-addiction tendencies than the remitting-ARHRPIU and persistent low-risk groups. Bullying problems were more severe in the emerging-ARHRPIU group, and the persistent-ARHRPIU group demonstrated the highest levels of suicidal ideation (Table 2).

\section{Longitudinal analysis}

The stepwise hierarchical binary logistic regression analysis was used to determine the contributing factors including hours of continuous Internet use, days-free-from-Internet-gaming, and the ADHD total, ADHD cognition, ADHD hyper-

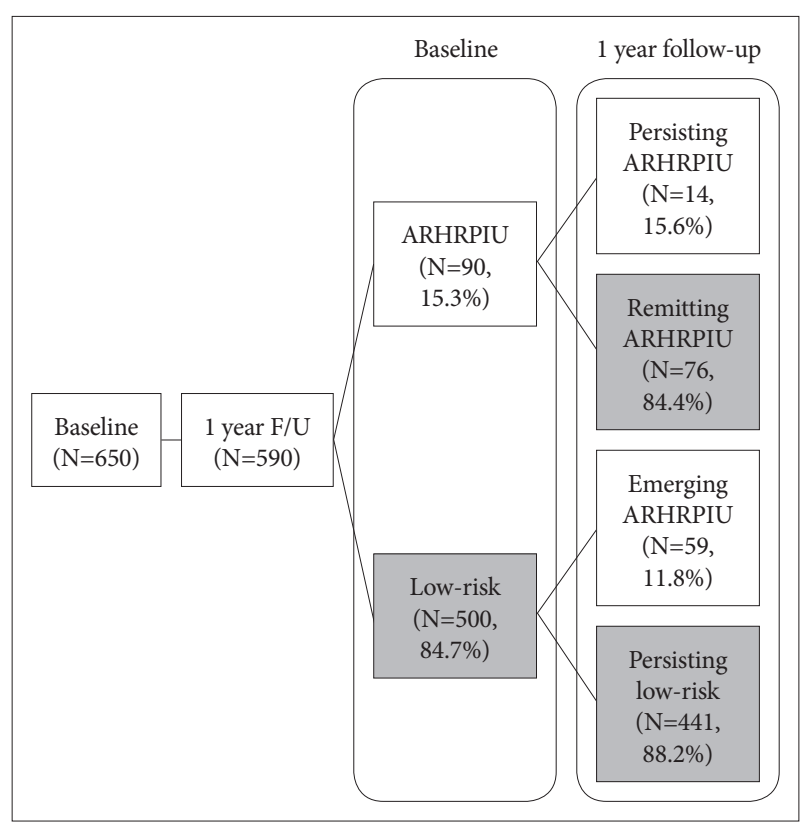

Figure 1. Transitions in ARHRPIU over a one-year period. ARHRPIU: at-risk/high-risk problematic Internet use. 
BY Choi et al.

Table 1. Comparisons of characteristics among the four groups at baseline

\begin{tabular}{|c|c|c|c|c|c|c|c|}
\hline \multirow[b]{2}{*}{ Characters } & \multirow[b]{2}{*}{ Factors } & \multicolumn{2}{|c|}{ Problematic $(90,15.3 \%)$} & \multicolumn{2}{|c|}{ Low risk $(500,84.7 \%)$} & \multirow[b]{2}{*}{$\mathrm{p}$-value } & \multirow[b]{2}{*}{$\begin{array}{l}\text { Post-hoc } \\
\text { comparison }\end{array}$} \\
\hline & & $\begin{array}{c}\text { Persistent } \\
\text { ARHRPIU (P) } \\
(14,2.4 \%)\end{array}$ & $\begin{array}{c}\text { Remitting } \\
\text { ARHRPIU (R) } \\
(76,12.9 \%)\end{array}$ & $\begin{array}{c}\text { Emerging } \\
\text { ARHRPIU (E) } \\
(59,10.0 \%)\end{array}$ & $\begin{array}{c}\text { Persistent } \\
\text { low risk (L) } \\
(441,74.7 \%)\end{array}$ & & \\
\hline Age (year) & & $13.64 \pm 0.50$ & $13.55 \pm 0.50$ & $13.44 \pm 0.50$ & $13.40 \pm 0.49$ & & \\
\hline \multirow[t]{4}{*}{ KS-II } & Total & $37.79 \pm 9.29$ & $32.31 \pm 9.55$ & $34.37 \pm 6.55$ & $30.63 \pm 8.71$ & $<0.01$ & $\mathrm{P}, \mathrm{E}>\mathrm{L}$ \\
\hline & Disturbance & $12.21 \pm 3.79$ & $9.68 \pm 3.82$ & $10.92 \pm 2.92$ & $9.11 \pm 3.41$ & $<0.01$ & $\mathrm{P}, \mathrm{E}>\mathrm{L}$ \\
\hline & Withdrawal & $11.36 \pm 2.68$ & $10.62 \pm 2.28$ & $10.58 \pm 1.73$ & $10.20 \pm 2.23$ & 0.09 & \\
\hline & Tolerance & $10.00 \pm 3.06$ & $8.49 \pm 3.36$ & $8.97 \pm 2.77$ & $7.93 \pm 3.15$ & $<0.01$ & \\
\hline \multirow{4}{*}{$\begin{array}{l}\text { Internet use } \\
\text { patterns }\end{array}$} & Hours at once & $2.14 \pm 1.05$ & $1.81 \pm 1.28$ & $2.41 \pm 1.19$ & $1.83 \pm 1.62$ & $<0.05$ & $\mathrm{E}>\mathrm{L}$ \\
\hline & $\begin{array}{l}\text { Hours during } \\
\text { school days }\end{array}$ & $2.04 \pm 1.14$ & $1.56 \pm 2.31$ & $1.79 \pm 1.35$ & $1.35 \pm 1.87$ & 0.21 & \\
\hline & $\begin{array}{l}\text { Hours during } \\
\text { weekends }\end{array}$ & $2.93 \pm 1.77$ & $2.66 \pm 3.97$ & $3.09 \pm 1.98$ & $2.48 \pm 2.19$ & 0.31 & \\
\hline & $\begin{array}{l}\text { Internet-game-free } \\
\text { days per week }\end{array}$ & $2.64 \pm 2.54$ & $3.98 \pm 2.47$ & $2.85 \pm 2.26$ & $4.01 \pm 2.46$ & $<0.01$ & $\mathrm{P}, \mathrm{E}<\mathrm{R}, \mathrm{L}$ \\
\hline \multirow[t]{4}{*}{ ADHD } & Total & $32.08 \pm 17.07$ & $21.11 \pm 12.55$ & $26.60 \pm 16.11$ & $19.99 \pm 12.28$ & $<0.01$ & $\mathrm{P}, \mathrm{E}>\mathrm{R}, \mathrm{L}$ \\
\hline & Cognition & $16.31 \pm 9.60$ & $10.56 \pm 6.80$ & $14.00 \pm 8.29$ & $10.18 \pm 6.44$ & $<0.01$ & $\mathrm{P}, \mathrm{E}>\mathrm{R}, \mathrm{L}$ \\
\hline & Hyperactivity & $11.62 \pm 5.58$ & $7.15 \pm 4.48$ & $8.72 \pm 5.99$ & $6.79 \pm 4.46$ & $<0.01$ & $\mathrm{P}>\mathrm{E}, \mathrm{R}, \mathrm{L}$ \\
\hline & Conduct & $4.29 \pm 2.52$ & $3.36 \pm 2.50$ & $3.86 \pm 2.77$ & $3.13 \pm 2.54$ & 0.08 & \\
\hline \multirow[t]{4}{*}{ Aggression } & Physical & $24.42 \pm 10.38$ & $22.92 \pm 6.39$ & $23.16 \pm 6.04$ & $21.51 \pm 6.56$ & 0.07 & \\
\hline & Verbal & $11.33 \pm 4.92$ & $12.79 \pm 4.47$ & $13.75 \pm 4.29$ & $12.48 \pm 4.10$ & 0.11 & \\
\hline & Rage & $18.75 \pm 6.69$ & $16.71 \pm 5.03$ & $18.54 \pm 5.50$ & $16.80 \pm 4.80$ & 0.05 & \\
\hline & Hostility & $21.25 \pm 10.23$ & $19.53 \pm 7.19$ & $21.21 \pm 6.58$ & $18.37 \pm 6.58$ & 0.01 & $\mathrm{E}>\mathrm{L}$ \\
\hline \multirow[t]{3}{*}{ Anger } & Expression & $20.07 \pm 5.98$ & $17.05 \pm 4.27$ & $18.32 \pm 5.73$ & $17.16 \pm 4.59$ & 0.04 & $\mathrm{P}=\mathrm{E}>\mathrm{R}, \mathrm{L}$ \\
\hline & Inhibition & $17.71 \pm 5.68$ & $16.08 \pm 4.55$ & $17.58 \pm 5.03$ & $16.33 \pm 4.53$ & 0.15 & \\
\hline & Control & $20.57 \pm 4.77$ & $20.12 \pm 4.88$ & $19.88 \pm 5.29$ & $20.29 \pm 4.63$ & 0.92 & \\
\hline
\end{tabular}

Data expressed as mean \pm SD. Intergroup-comparison one-way ANOVA followed by post-hoc analysis by Scheffe's method. KS-II: Internet Addiction Proneness Scale for Youth Test, ARHRPIU: at-risk/high-risk problematic Internet use, ADHD: attention-deficit/hyperactivity disorder

Table 2. Characteristics of the four groups at one-year follow-up

\begin{tabular}{|c|c|c|c|c|c|c|c|}
\hline \multirow[b]{2}{*}{ Characters } & \multirow[b]{2}{*}{ Factors } & \multicolumn{2}{|c|}{ Problematic $(90,15.3 \%)$} & \multicolumn{2}{|c|}{ Low risk $(500,84.7 \%)$} & \multirow[b]{2}{*}{$\mathrm{p}$-value } & \multirow[b]{2}{*}{$\begin{array}{l}\text { Post-hoc } \\
\text { Comparison }\end{array}$} \\
\hline & & $\begin{array}{c}\text { Persistent } \\
\text { ARHRPIU (P) } \\
(14,2.4 \%)\end{array}$ & $\begin{array}{c}\text { Remitting } \\
\text { ARHRPIU (R) } \\
(76,12.9 \%)\end{array}$ & $\begin{array}{c}\text { Emerging } \\
\text { ARHRPIU (E) } \\
(59.10 .0 \%)\end{array}$ & $\begin{array}{c}\text { Persistent } \\
\text { Low-risk (L) } \\
(441,74.7 \%)\end{array}$ & & \\
\hline \multirow[t]{2}{*}{ School problems } & Bullying & $3.14 \pm 5.49$ & $3.18 \pm 4.47$ & $7.33 \pm 7.90$ & $4.35 \pm 6.62$ & $<0.01$ & $\mathrm{E}, \mathrm{L}>\mathrm{P}, \mathrm{R}$ \\
\hline & Bullied & $3.00 \pm 5.16$ & $2.95 \pm 4.22$ & $7.36 \pm 8.74$ & $3.31 \pm 5.27$ & $<0.01$ & $\mathrm{E}>\mathrm{P}, \mathrm{R}, \mathrm{L}$ \\
\hline Depression & BDI & $10.77 \pm 17.78$ & $5.65 \pm 6.49$ & $8.51 \pm 9.45$ & $4.63 \pm 5.82$ & $<0.01$ & $\mathrm{P}, \mathrm{E}>\mathrm{R}, \mathrm{L}$ \\
\hline Suicidality & Suicide ideation & $33.23 \pm 52.05$ & $10.06 \pm 18.69$ & $15.81 \pm 26.10$ & $7.28 \pm 14.64$ & $<0.01$ & $\mathrm{P}>\mathrm{E}, \mathrm{R}, \mathrm{L}$ \\
\hline Other addiction & $\begin{array}{l}\text { Smart phone } \\
\text { addiction }\end{array}$ & $30.69 \pm 5.98$ & $29.21 \pm 6.95$ & $33.77 \pm 7.45$ & $29.14 \pm 7.12$ & $<0.01$ & $\mathrm{E}, \mathrm{P}>\mathrm{R}, \mathrm{L}$ \\
\hline \multirow[t]{4}{*}{ Impulsivity } & Total & $26.21 \pm 12.73$ & $23.96 \pm 9.31$ & $28.85 \pm 8.52$ & $24.04 \pm 9.48$ & $<0.01$ & \\
\hline & Cognitive & $16.36 \pm 2.27$ & $14.96 \pm 2.50$ & $15.75 \pm 2.42$ & $15.05 \pm 2.60$ & 0.07 & \\
\hline & Nonplanning & $23.46 \pm 3.26$ & $22.13 \pm 3.40$ & $22.69 \pm 3.02$ & $21.85 \pm 3.94$ & 0.209 & \\
\hline & Motor & $17.57 \pm 5.81$ & $15.47 \pm 3.17$ & $17.36 \pm 3.66$ & $14.99 \pm 3.47$ & $<0.01$ & $\mathrm{P}, \mathrm{E}>\mathrm{R}>\mathrm{L}$ \\
\hline
\end{tabular}

Data expressed as mean \pm standard deviation. Intergroup-comparison one-way ANOVA followed by post-hoc analysis by Scheffe's method. ARHRPIU: at-risk/high-risk problematic Internet use, BDI: Beck's Depression Inventory 
kinetic, Aggression hostility, and Anger expression scores which had statistical significance in the four groups and was also used to predict transitions to remittance from ARHRPIU and the emergence of ARHRPIU.

The factors that linked statistically to the transitions included the ADHD hyperkinetic subscale score for ARHRPIU remittance, and the ADHD cognitive subscale score and Internet-free days for ARHRPIU emergence (Table 3). The findings indicate that individuals exhibiting a higher hyperkinetic ADHD score were less likely to remit from ARHRPIU and that individuals exhibiting a greater ADHD cognitive dysfunction and reporting fewer Internet-free days were more likely to demonstrate an emergence of ARHRPIU.

\section{DISCUSSION}

The current study sought to examine the factors associated with the prevalence in transitions from low-risk Internet use to ARHRPIU and from ARHRPIU to low-risk Internet use in a group of middle-school boys. Our a priori hypothesis regarding the involvement of ADHD features was supported. There was also some evidence to support a potential role for temperamental features relating to anger and aggression, albeit not in the predictive models. Internet-game-free days was identified as a factor linked to emerging ARHRPIU. Taken together, these findings suggest potential targets for interventions aimed at limiting the emergence and promoting the remittance of ARHRPIU.

\section{Prevalence}

Prevalence estimates for PIU vary widely from less than $1 \%$ to about $50 \%$, depending on the cut-off values, the population being studied, and other factors. ${ }^{5,40,45,74,75}$ In the current study, the prevalence of ARHRPIU at baseline and at one year was similar, in the range of $12-15 \%$. The relatively low threshold for defining ARHRPIU in the current study may have generated higher estimates than in other studies, which use more stringent thresholds. The prevalence rates in this study were determined solely by the Internet Addiction Proneness Scale for Youth Test (KS-II) ${ }^{55-57}$ which was developed and standardized by the National Information Agency; there are no other validating processes to be found in the literature. Other possible reasons for the higher prevalence rates might be that our sample included only boys, and that Korea may have a higher prevalence of PIU than other countries. Cheng and $\mathrm{Li}^{76}$ suggested that accessibility of the Internet and quality of (real) life could be used to explain cross-national variations in prevalence estimates of Internet addiction. According to the Organization for Economic Co-operation and Development's (OECD) 2011 broadband statistics, ${ }^{77}$ South Korea's wireless broadband penetration is amongst the highest in the world. This environment, in conjunction with academic stress, may in part promote the use of the Internet as regards behaviors like video-gaming, social networking, gambling, pornography viewing, or other potentially addictive behaviors, consistent with the high prevalence estimates of PIU observed in Korean boys. ${ }^{78}$

\section{ARHRPIU emergence}

Multiple factors have been suggested to affect the development of PIU, including high impulsivity, low social competence, poor emotional regulation, and spending more time on the Internet. Similar to previous results, ${ }^{40,45,79}$ the duration of Internet use sessions, gaming days per week, general inattention, hostility and anger expression were higher in those with emerging ARHRPIU than in the persistent low-risk Internet use group. The cognitive features of ADHD and the number of Internet-game-free days predicted transitions to ARHRPIU at one year. These findings suggest that interventions assessing for and targeting ADHD, particularly its cognitive features, may prevent the emergence of PIU in youths. 80 Similarly, increasing the number of Internet-game-free days, as might be implemented by caregivers (parents and others), may represent another important mechanism for preventing PIU in young people. ${ }^{80}$ At one-year follow-up, the emerging-ARHRPIU group experienced more school problems, depression, smartphone addiction tendencies, and motor impulsivity than the low-risk group. The current findings resonate with prior findings linking ADHD, hostility, depression, and anxiety to PIU. ${ }^{80,81}$ In the emerging-ARHRPIU group, school problems, including bullying or being bullied, were notably higher than in the other groups. It is possible

Table 3. Factors predicting transitions at one-year follow-up

\begin{tabular}{llccrccc}
\hline \multicolumn{1}{c}{ Transitions } & \multicolumn{1}{c}{ Factors } & B & SE & Wald & p-value & Exp (B) & 95\% CI \\
\hline ARHRPIU & Days of internet game free & -0.21 & 0.07 & 9.55 & $<0.01$ & 0.81 & $0.71-0.93$ \\
emergence & Cognitive ADHD & 0.08 & 0.02 & 13.92 & $<0.01$ & 1.08 & $1.04-1.11$ \\
ARHRPIU & Hyperkinetic ADHD & -0.30 & 0.11 & 7.87 & $<0.01$ & 1.38 & $0.60-0.92$ \\
remittance & & & & & & & \\
\hline
\end{tabular}

Binary logistic regression analysis. B: $\beta$ values are the estimated unstandardized regression coefficients, SE: standard error, CI: confidence interval, ARHRPIU: at-risk/high-risk problematic Internet use, ADHD: attention-deficit/hyperactivity disorder 
that school stress related to bullying or being bullied may motivate adolescents to increase their Internet use in a problematic fashion. Other factors, for example those relating to depression and suicidal ideation, were high in both the persistent- and emerging-ARHRPIU groups, and these findings are both consistent with prior findings and suggest the need for targeting mood and related psychiatric concerns among ARHRPIU youths. ${ }^{82}$

\section{ARHRPIU persistence and remittance}

The group with persistent ARHRPIU showed more Internet-gaming days per week, higher ADHD scores, and greater anger expression at baseline and after one year; they also had higher depression scores, suicidality, smartphone-addiction tendencies, and motor impulsivity than the other groups. Gentile and colleagues ${ }^{41}$ reported that, 'once adolescents became pathological video gamers, they began to have poorer grades and poorer relationships'. Although only a small portion $(2.4 \%)$ of our sample showed persistent ARHRPIU, they appeared to have the greatest psychopathology, including higher depression, suicidal ideation, and impulsivity scores. The main factor linking a transition from ARHRPIU to lowrisk Internet use was lower levels of ADHD hyperkinesis. This finding suggests that youths who mature and develop better motor control may simultaneously be better able to control their behavior related to Internet use. Furthermore, these findings raise the possibility that by assessing for and targeting ADHD hyperkinesis, it may be possible to help youths transition to less problematic levels of Internet use.

Depression and suicidal ideation scores were significantly higher in the persistent-ARPIU group than the other groups, followed by the emerging-ARPIU group. Depression and low self-esteem are important considerations in adolescent suicidality, with bullying and PIU possibly contributing to suicidality both directly and indirectly. ${ }^{83}$ Young $^{84}$ proposed that lonely people may fulfill unsatisfied social needs through virtual means, leading to PIU, greater social isolation, and depression. Bullying may lead to serious mental and physical sequelae, and the victims of chronic school bullying may be at a greater risk of suicidal and aggressive behaviors. ${ }^{82}$ In addition, cyberbullying is an important concern and may lead to victims and perpetrators feeling more depressed, lonely, and isolated, thus impairing social relationships and promoting suicidal tendencies. The data suggest that victims and perpetrators of bullying may use the Internet for longer periods of time and with a greater frequency, and so may be more prone to PIU. ${ }^{85}$ They may also have higher expectations regarding Internet use and virtual interpersonal relationships, which itself may promote PIU.

\section{The stability of ARHRPIU}

Spontaneous recovery has been reported for addictive behaviors including substance-use problems, with $40 \%$ of recoveries for alcohol-use problems involving low-risk drinking, ${ }^{86}$ and the personal history of smokers consuming no more than 10 cigarettes per day being observed to be considerably fluid. ${ }^{87}$ Similar to other potentially addictive behaviors and disorders, PIU may have a high rate of spontaneous recovery. King et al. ${ }^{43}$ reported that $75 \%$ of individuals with PIU ceased to exhibit problematic behaviors at a two-year follow-up, and a recently published study reported that only $1 \%$ of pathological gamers remained pathological after two years. ${ }^{36}$ In contrast, Gentile et al. ${ }^{41}$ found that $84 \%$ of pathological gamers were still pathological gamers two years later; other studies have found that about $50 \%$ of pathological gamers remained pathological gamers one year later. ${ }^{16,45}$ There is no consensus regarding the pathways that might discriminate between those who continue to exhibit PIU and those who do not, or between those who, over time, develop PIU and those who do not. With respect to natural spontaneous recovery, Shaffer and colleagues proposed an adaptation model for gambling: ${ }^{88-92}$ individuals adapt relatively quickly after exposure to gambling opportunities are changed and frequently transition between levels of problem-gambling severity, including from more problematic to less problematic levels. In the current study, only $15.6 \%$ of individuals exhibiting ARHRPIU at baseline continued to have ARHRPIU one year later, and $11.8 \%$ of individuals exhibiting low-risk behaviors at baseline transitioned to having ARHRPIU. Thus, while the overall prevalence of ARHRPIU remained comparable at both time points, the individuals exhibiting ARHRPIU were largely different. Multiple possibilities may explain these seemingly volatile transitions. Firstly, the mean age of the sample was low. Scharkow et al..$^{45}$ reported that for adults aged 40 years and older, stability was very high for periods of up to four years; however, adolescents show less stability, and our study included youths between 12 and 15 years old. Secondly, compared with addictive behaviors in adults, adolescent addictive behaviors may be more affected by environmental, psychological, and relational factors. PIU in adolescents may represent a 'phase' of development, or a 'phase' precipitated by acute or transient stressful situations. The findings, when considered in this context, suggest that proper preventive approaches should be considered, developed, and implemented at this important stage in a young person's development.

\section{Strengths, limitations, and conclusions}

In this study, some limitations should be noted. Firstly, the investigation was based on self-reported data, which are subject to recall biases amongst others. Secondly, the sample 
consisted solely of middle-school boys. A further study of females and other age groups is needed. Thirdly, although it was a prospective study, the follow-up period was one year, and future studies of longer durations are warranted. Finally, except for the Internet addiction scale, different psychological scales were used at baseline and one-year follow-up. The use of a broader range of assessments at both times (which, in our study, was limited by subject burden) may have identified different factors linked to transitions in PIU severity. Furthermore, the Internet Addiction Proneness Scale for Youth Test (KS-II) ${ }^{55-57}$ was developed and standardized by the National Information Society Agency, however, there are no other validating processes regarding the KS-II in the literature. Despite these limitations, the present findings support the previous studies in that specific negative-health features are linked to transitions in ARHRPIU. Furthermore, the findings suggest that interventions are needed and may be best targeted at specific groups of youths.

\section{Acknowledgments}

The authors wish to thank the staffs of the Chuncheon Community Addiction Center and Chuncheon Office of Education for their efforts and contributions. We also would like to express our gratitude to the participants for their time and cooperation for this study.

\section{Conflicts of Interest}

The authors have no potential conflicts of interest to disclose.

\section{Author Contributions}

Conceptualization: Sang-Kyu Lee. Data curation: Bo Young Choi, Sun Huh, Dai-Jin Kim, Sang Won Suh. Formal analysis: Bo Young Choi, Sun Huh, Dai-Jin Kim, Sang Won Suh, Sang-Kyu Lee. Funding: Sang-Kyu Lee. Investigation: Bo Young Choi, Sang Won Suh, Sang-Kyu Lee. Methodology: Sang Won Suh, Sang-Kyu Lee, Marc N. Potenza. Supervision: SangKyu Lee. Visualization: Sang Won Suh, Sang-Kyu Lee, Marc N. Potenza. Writing_original draft: Bo Young Choi, Sang-Kyu Lee. Writing-review \& editing: Bo Young Choi, Sun Huh, Dai-Jin Kim, Sang Won Suh, SangKyu Lee, Marc N. Potenza.

\section{ORCID iDs}

$\begin{array}{ll}\text { Sang-Kyu Lee } & \text { https://orcid.org/0000-0001-6714-850X } \\ \text { Bo Young Cho } & \text { https://orcid.org/0000-0002-9579-3503 }\end{array}$

\section{REFERENCES}

1. Shapira NA, Lessig MC, Goldsmith TD, Szabo ST, Lazoritz M, Gold MS, et al. Problematic internet use: proposed classification and diagnostic criteria. Depress Anxiety 2003;17:207-216.

2. Paik A, Oh D, Kim D. A case of withdrawal psychosis from internet addiction disorder. Psychiatry Investig 2014;11:207-209.

3. Kaur J, Bhatia MS, Gautam P. Internet sex addiction and its negative consequences: a report. J Clin Diagn Res 2015;9:VL01.

4. Morrison CM, Gore H. The relationship between excessive internet use and depression: a questionnaire-based study of 1,319 young people and adults. Psychopathology 2010;43:121-126.

5. Liu TC, Desai RA, Krishnan-Sarin S, Cavallo DA, Potenza MN. Problematic internet use and health in adolescents: data from a high school survey in Connecticut. J Clin Psychiatry 2011;72:836-845.

6. Yau YH, Pilver CE, Steinberg MA, Rugle LJ, Hoff RA, Krishnan-Sarin
S, et al. Relationships between problematic internet use and problemgambling severity: findings from a high-school survey. Addict Behav 2014;39:13-21.

7. Kong G, Tsai J, Pilver CE, Tan HS, Hoff RA, Cavallo DA, et al. Differences in gambling problem severity and gambling and health/functioning characteristics among Asian-American and Caucasian highschool students. Psychiatry Res 2013;210:1071-1078.

8. Leung L. Predicting internet risks: a longitudinal panel study of gratifications-sought, internet addiction symptoms, and social media use among children and adolescents. Health Psychol Behav Med 2014;2: 424-439.

9. Casey BJ, Getz S, Galvan A. The adolescent brain. Dev Rev 2008;28:62-77.

10. Liu CY, Kuo FY. A study of internet addiction through the lens of the interpersonal theory. Cyberpsychol Behav 2007; 10: 799-804.

11. Hybels S. Cited in “terminal addiction". Internet Comms Today 1995;4:35.

12. Shotton MA. The costs and benefits of 'computer addiction'. Behav Inf Technol 1991;10:219-230.

13. Pratarelli ME, Browne BL, Johnson K. The bits and bytes of computer/ Internet addiction: a factor analytic approach. Behav Res Methods Instrum Comput 1999;31:305-314.

14. Rumpf HJ, Vermulst AA, Bischof A, Kastirke N, Gurtler D, Bischof G, et al. Occurence of internet addiction in a general population sample: a latent class analysis. Eur Addict Res 2014;20:159-166.

15. Brenner V. Psychology of computer use: XLVII. Parameters of Internet use, abuse and addiction: the first 90 days of the Internet Usage Survey. Psychol Rep1997;80:879-882.

16. Van Rooij AJ, Schoenmakers TM, Vermulst AA, Van den Eijnden RJ, Van de Mheen D. Online video game addiction: identification of addicted adolescent gamers. Addiction 2011;106:205-212.

17. Gentile DA, Choo H, Liau A, Sim T, Li D, Fung D, et al. Pathological video game use among youths: a two-year longitudinal study. Pediatrics 2011;127:e319-e329.

18. Bahrainian SA, Alizadeh KH, Raeisoon MR, Gorji OH, Khazaee A. Relationship of Internet addiction with self-esteem and depression in university students. J Prev Med Hyg 2014;55:86-89.

19. Young KS. Psychology of computer use: XL. Addictive use of the Internet: a case that breaks the stereotype. Psychol Rep 1996;79:899-902.

20. Choi JS, Park SM, Roh MS, Lee JY, Park CB, Hwang JY, et al. Dysfunctional inhibitory control and impulsivity in Internet addiction. Psychiatry Res 2014;215:424-428.

21. Petrie H, Gunn DA. Internet "addiction": the effects of sex, age, depression and introversion. Br Psychol Soc London Conf 1998;15.

22. GBD 2013 DALYs and HALE Collaborators, Murray CJ, Barber RM, Foreman KJ, Abbasoglu Ozgoren A, Abd-Allah F, et al. Global, region$\mathrm{al}$, and national disability-adjusted life years (DALYs) for 306 diseases and injuries and healthy life expectancy (HALE) for 188 countries, 1990-2013: quantifying the epidemiological transition. Lancet 2015; 386:2145-2191.

23. Young KS, Rogers RC. The relationship between depression and internet addiction. Cyberpsychol Behav 1998;1:25-28.

24. Treuer T, Fábián Z, Füredi J. Internet addiction associated with features of impulse control disorder: is it a real psychiatric disorder? J Affect Disord 2001;66:283.

25. Cho NK, Yang DK. The relationship among perceived adolescents' social supports, internet addiction tendency and internet-related delinquency. Kor J Develop Psychol 2001;14:91-111.

26. Jung YE, Leventhal B, Kim YS, Park TW, Lee SH, Lee M, et al. Cyberbullying, problematic internet use, and psychopathologic symptoms among Korean youth. Yonsei Med J 2014;55:826-830.

27. Kim YS, Leventhal BL, Koh YJ, Hubbard A, Boyce WT. School bullying and youth violence: causes or consequences of psychopathologic behavior? Arch Gen Psychiatry 2006;63:1035-1041.

28. Kim YR, Son JW, Lee SI, Shin CJ, Kim SK, Ju G, et al. Abnormal brain activation of adolescent internet addict in a ball-throwing animation task: possible neural correlates of disembodiment revealed by fMRI. 
Prog Neuropsychopharmacol Biol Psychiatry 2012;39:88-95.

29. Lin F, Zhou Y, Du Y, Qin L, Zhao Z, Xu J, et al. Abnormal white matter integrity in adolescents with internet addiction disorder: a tract-based spatial statistics study. PLoS One 2012;7:e30253.

30. Yuan K, Qin W, Wang G, Zeng F, Zhao L, Yang X, et al. Microstructure abnormalities in adolescents with internet addiction disorder. PLoS One 2011;6:e20708.

31. Park MH, Park EJ, Choi J, Chai S, Lee JH, Lee C, et al. Preliminary study of Internet addiction and cognitive function in adolescents based on IQ tests. Psychiatry Res 2011;190:275-281.

32. Tsitsika A, Critselis E, Louizou A, Janikian M, Freskou A, Marangou E, et al. Determinants of Internet addiction among adolescents: a casecontrol study. ScientificWorldJournal 2011;11:866-874.

33. Kim Y, Park JY, Kim SB, Jung IK, Lim YS, Kim JH. The effects of Internet addiction on the lifestyle and dietary behavior of Korean adolescents. Nutr Res Pract 2010;4:51-57.

34. Milani L, Osualdella D, Di Blasio P. Quality of interpersonal relationships and problematic Internet use in adolescence. Cyberpsychol Behav 2009;12:681-684.

35. Lam LT, Peng Z, Mai J, Jing J. The association between internet addiction and self-injurious behaviour among adolescents. Inj Prev 2009; 15:403-408.

36. Kuss DJ, Griffiths MD, Karila L, Billieux J. Internet addiction: a systematic review of epidemiological research for the last decade. Curr Pharm Des 2014;20:4026-4052.

37. Kuss DJ, Griffiths MD. Internet and gaming addiction: a systematic literature review of neuroimaging studies. Brain Sci 2012;2:347-374.

38. King DL, Delfabbro PH. Internet gaming disorder treatment: a review of definitions of diagnosis and treatment outcome. J Clin Psychol 2014;70:942-955.

39. Chang FC, Chiu CH, Miao NF, Chen PH, Lee CM, Chiang JT, et al. The relationship between parental mediation and Internet addiction among adolescents, and the association with cyberbullying and depression. Compr Psychiatry 2015;57:21-28.

40. Strittmatter E, Parzer P, Brunner R, Fischer G, Durkee T, Carli V, et al. A 2-year longitudinal study of prospective predictors of pathological Internet use in adolescents. Eur Child Adolesc Psychiatry 2016;25:725-734.

41. Gentile DA, Choo H, Liau A, Sim T, Li D, Fung D, et al. Pathological video game use among youths: a two-year longitudinal study. Pediatrics 2011;127:e319-e329.

42. Kushnir V, Cunningham JA, Hodgins DC. A prospective natural history study of quitting or reducing gambling with or without treatment: protocol. JMIR Res Protoc 2013;2:e51.

43. King DL, Delfabbro PH, Griffiths MD. Trajectories of problem video gaming among adult regular gamers: an 18-month longitudinal study. Cyberpsychol Behav Soc Netw 2013;16:72-76.

44. van Rooij AJ, Schoenmakers TM, van de Eijnden RJ, van de Mheen D. Compulsive internet use: the role of online gaming and other internet applications. J Adolesc Health 2010;47:51-57.

45. Scharkow M, Festl R, Quandt T. Longitudinal patterns of problematic computer game use among adolescents and adults-a 2-year panel study Longitudinal patterns of problematic gaming. Addiction 2014; 109:1910-1917.

46. Paulson JF, Buermeyer C, Nelson-Gray RO. Social rejection and ADHD in young adults: an analogue experiment. J Atten Disord 2005; 8:127-135

47. Wehmeier PM, Schacht A, Barkley RA. Social and emotional impairment in children and adolescents with ADHD and the impact on quality of life. J Adolesc Health 2010;46:209-217.

48. Brook U, Boaz M. Attention deficit and hyperactivity disorder (ADHD) and learning disabilities (LD): adolescents perspective. Patient Educ Couns 2005;58:187-191.

49. Blackman GL, Ostrander R, Herman KC. Children with ADHD and depression: a multisource, multimethod assessment of clinical, social, and academic functioning. J Atten Disord 2005;8:195-207.
50. Kraut R, Patterson M, Lundmark V, Kiesler S, Mukopadhyay T, Scherlis W. Internet paradox. A social technology that reduces social involvement and psychological well-being? Am Psychol 1998;53:1017-1031.

51. Black DW, Belsare G, Schlosser S. Clinical features, psychiatric comorbidity, and health-related quality of life in persons reporting compulsive computer use behavior. J Clin Psychiatry 1999;60:839-844.

52. Shapira NA, Goldsmith TD, Keck PE Jr, Khosla UM, McElroy SL. Psychiatric features of individuals with problematic internet use. J Affect Disord 2000;57:267-272.

53. Yen JY, Ko CH, Yen CF, Chen SH, Chung WL, Chen CC. Psychiatric symptoms in adolescents with Internet addiction: comparison with substance use. Psychiatry Clin Neurosci 2008;62:9-16.

54. Cho H, Kwon M, Choi JH, Lee SK, Choi JS, Choi SW, et al. Development of the Internet addiction scale based on the Internet Gaming Disorder criteria suggested in DSM-5. Addict Behav 2014;39:1361-1366.

55. National Information Society Agency Report. Third Standardization of Korean Internet Addiction Proneness Scale. Seoul; National Information Society Agency: 2011.

56. Kim D, Lee Y, Lee J, Nam JK, Chung Y. Development of Korean smartphone addiction proneness scale for youth. PLoS One 2014;9:e97920.

57. Sin G, Kim D, Jeung Y. Third Standardization of Korean Internet Addiction Proneness Scale. Seoul: National Information Society Agency 2011.

58. Conners CK, Wells KC, Parker JD, Sitarenios G, Diamond JM, Powell JW. A new self-report scale for assessment of adolescent psychopathology: factor structure, reliability, validity, and diagnostic sensitivity. J Abnorm Child Psychol 1997;25:487-497.

59. Conners CK. Conners' Rating Scales-Revised. Toronto: Multi-Health Systems; 1997.

60. Bahn GH, Shin MS, Cho SC, Hong KE. A preliminary study for the development of the assessment scale for ADHD in adolescents: Reliability and validity for Cass(C). J Korean Acad Child Adolesc Psychiatry 2001;12:218-224.

61. Buss AH, Perry M. The aggression questionnaire. J Pers Soc Psychol 1992;63:452-459.

62. Seo SG, Kwon SM. Validation study of the Korean version of the aggression questionnaire. Korean J Clin Psychol 2002;21:487-501.

63. Chon KK, Hahn DW, Lee CH, Spielberger C. Korean adaptation of the state-trait anger expression inventory: anger and blood pressure. Korean J Health Psychol 1997;2:60-78.

64. Reynolds WM. Suicidal Ideation Questionnaire (SIQ): Professional manual. Odessa, FL; Psychological Assessment Resources;1987.

65. Shin MS. A study of suicidal ideation among high school students: the structural relation among depression, hopelessness, and suicidal ideation. Korean J Clin Psychol 1990;9:1-19.

66. Mazza JJ, Reynolds WM. Exposure to violence in young inner-city adolescents: relationships with suicidal ideation, depression, and PTSD symptomatology. J Abnorm Child Psychol 1999;27:203-213.

67. Beck AT, Ward CH, Mendelson M, Mock J, Erbaugh J. An inventory for measuring depression. Arch Gen Psychiatry 1961;4:561-571.

68. Dolle K, Schulte-Korne G, O'Leary AM, von Hofacker N, Izat Y, Allgaier AK. The Beck depression inventory-II in adolescent mental health patients: cut-off scores for detecting depression and rating severity. Psychiatry Res 2012;200:843-848.

69. Hahn H, Yum TH, Shin YW, Kim KH, Yoon DJ, Chung KJ. A standardization study of Beck Depression Inventory in Korea. J Korean Neuropschiatr Assoc 1986;25:487-500.

70. Choi ES, Chae JH. A study of psychological factors associated with bullying. Underst People 2000;21:109-137.

71. Kwon M, Kim DJ, Cho H, Yang S. The smartphone addiction scale: development and validation of a short version for adolescents. PLoS One 2013;8:e83558.

72. Fossati A, Di Ceglie A, Acquarini E, Barratt ES. Psychometric properties of an Italian version of the Barratt Impulsiveness Scale-11 (BIS-11) in nonclinical subjects. J Clin Psychol 2001;57:815-828.

73. Lee SR, Lee WH, Park JS, Kim SM, Kim JW, Shim JH. The study on 
reliability and validity of Korean version of the Barratt Impulsiveness Scale-11-Revised in nonclinical adult subjects. J Korean Neuropsychiatr Assoc 2012;51:378-386

74. Petry NM, O'Brien CP. Internet gaming disorder and the DSM-5. Addiction 2013;108:1186-1187.

75. Lim JA, Gwak AR, Park SM, Kwon JG, Lee JY, Jung HY, et al. Are adolescents with internet addiction prone to aggressive behavior? The mediating effect of clinical comorbidities on the predictability of aggression in adolescents with internet addiction. Cyberpsychol Behav Soc Netw 2015;18:260-267.

76. Cheng C, Li AY. Internet addiction prevalence and quality of (real) life: a meta-analysis of 31 nations across seven world regions. Cyberpsychol Behav Soc Netw 2014;17:755-760.

77. OECD Telecommunications and Internet Statistics (database). Available at: https://doi.org/10.1787/data-00682-en. Accessed June 13, 2011.

78. Ha JH, Yoo HJ, Cho IH, Chin B, Shin D, Kim JH. Psychiatric comorbidity assessed in Korean children and adolescents who screen positive for Internet addiction. J Clin Psychiatry 2006;67:821-826.

79. Lee JY, Shin KM, Cho SM, Shin YM. Psychosocial risk factors associated with internet addiction in Korea. Psychiatry Investig 2014;11:380-386.

80. Ko CH, Liu TL, Wang PW, Chen CS, Yen CF, Yen JY. The exacerbation of depression, hostility, and social anxiety in the course of Internet addiction among adolescents: a prospective study. Compr Psychiatry 2014;55:1377-1384.

81. Ko CH, Yen JY, Chen CS, Yeh YC, Yen CF. Predictive values of psychiatric symptoms for internet addiction in adolescents: a 2-year prospective study. Arch Pediatr Adolesc Med 2009;163:937-943.

82. Kim YS, Koh YJ, Leventhal B. School bullying and suicidal risk in Korean middle school students. Pediatrics 2005;115:357-363.
83. Ryu EJ, Choi KS, Seo JS, Nam BW. The relationships of Internet addiction, depression, and suicidal ideation in adolescents. J Korean Acad Nurs 2004;34:102-110.

84. Young KS. Caught in the Net : How to Recognize the Signs of Internet Addiction-and a Winning Strategy for Recovery. New York, N.Y.: John Wiley \& Sons; 1998.

85. Kim YJ, Koh SH, Shin YM. Characteristics of internet use in relation to school bullying. J Korean Neuropsychiatr Assoc 2010;49:361-366.

86. Slutske WS. Natural recovery and treatment-seeking in pathological gambling: results of two U.S. national surveys. Am J Psychiatry 2006; 163:297-302.

87. Levy DE, Biener L, Rigotti NA. The natural history of light smokers: a population-based cohort study. Nicotine Tob Res 2009;11:156-163.

88. LaPlante DA, Shaffer HJ. Understanding the influence of gambling opportunities: expanding exposure models to include adaptation. Am J Orthopsychiatry 2007;77:616-623.

89. Shaffer H, Hall MN, Vander Bilt J. Estimating the Prevalence of Disordered Gambling Behavior in the United States and Canada : A MetaAnalysis. Boston, MA: Harvard College; 1997.

90. Shaffer HJ, Hall MN, Vander Bilt J. Estimating the prevalence of disordered gambling behavior in the United States and Canada: a research synthesis. Am J Public Health 1999;89:1369-1376.

91. Shaffer HJ, LaBrie RA, LaPlante D. Laying the foundation for quantifying regional exposure to social phenomena: considering the case of legalized gambling as a public health toxin. Psychol Addict Behav 2004; 18:40-48.

92. Shaffer H, Zinberg NE. The social psychology of intoxicant use: the natural history of social settings and social control. Bull Soc Psychol Addict Behav 1985;4:49-55. 